\title{
CrN/TiN/CrN thin films grown by pulsed DC sputtering
}

\author{
A. D. González-Escárcega*, D. Ortíz-Palacios*. C. Ornelas*, O. Solis*, H. E. Esparza-Ponce*, and
} A. Duarte-Moller*

* Centro de Investigación en Materiales Avanzados, S. C, Miguel de Cervantes 120, Complejo Industrial Chihuahua, Chihuahua Chih. 31109, México.

Hard coatings and their applications continuously are in progress [1]. The thin films of transition metals nitrides have a broad range of potential applications that goes from microelectronics to the metalmechanics industry or in biological implants. The research of nitrides of transition metals is still on in actuality for the different science branches like the above mentioned. Different techniques are used to grow thin films.

Thin films of CrN/TiN/CrN were grown on silicon substrate by using the INTERCOVAMEX-V3 DC sputtering system. Substrate temperature was of $300{ }^{\circ} \mathrm{C}$ and $200 \mathrm{~W}$ in the pulsed DC. The multilayer was obtained by growing $\mathrm{CrN}$ on $\mathrm{Si}$ at a nitrogen flow of $4.2 \mathrm{~cm}^{3} / \mathrm{min}$ during 15 minutes following of growing TiN with $6 \mathrm{~cm}^{3} /$ min for 15 minutes and finally $\mathrm{CrN}$ at $6 \mathrm{~cm}^{3} / \mathrm{min}$ during 15 minutes.

The cross section of the CrN/TiN/CrN appears in Fig. 1. As we can appreciate the thickness of each layer is approximately of $300 \mathrm{~nm}$. In the cross section preparation a gold coating was used in order to improve the FIB process. A JEOL JSM200FS field emission TEM was used in order to obtain the HR images.

Fig. 2 displays the interface TiN/CrN where a high ordered structure is appreciable. The figure shows that the TiN has been grown in the (111) direction, which is the right structure to have a best and hard interface between the $\mathrm{CrN}$ layers. In this case a hardness test it gave as result $44 \mathrm{RC}$. This hardness value is in good agreement with those reported for similar systems [2].

The growing conditions with pulsed DC sputtering technique to obtain the stoichiometry $\mathrm{CrN} / \mathrm{TiN} / \mathrm{CrN}$ were established. A very strong dependence of the $\mathrm{N}$ partial pressure in the conditions for the film deposition is exhibited. The experiment was reproduced and the results were exactly the same.

References

[1] Y.G. Shen, Y.W. Mai, W.E. McBride, Q.C. Zhang, D.R. McKenzie, Thin Solid Films 372 (2000) 257.

[2] BryCoat Inc. All rights reserved. Copyright 2003. 


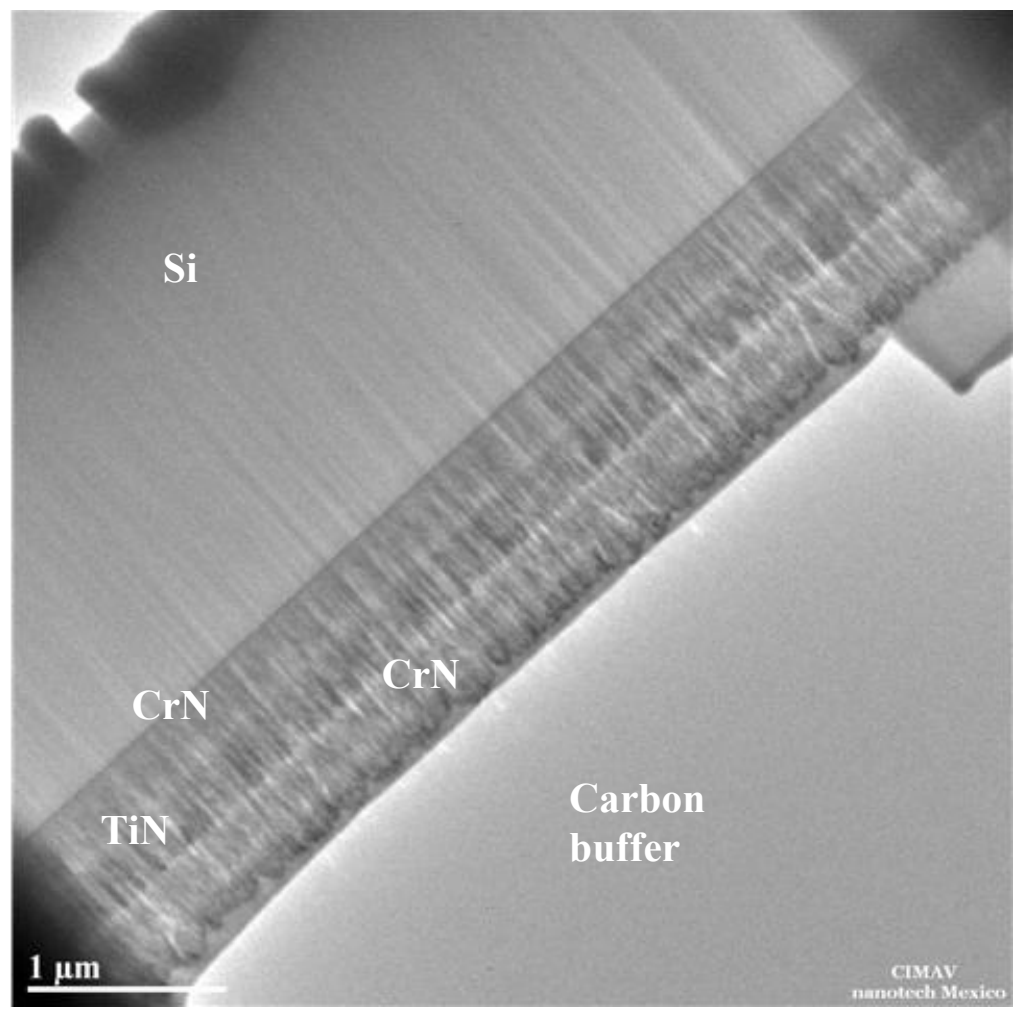

FIG. 1

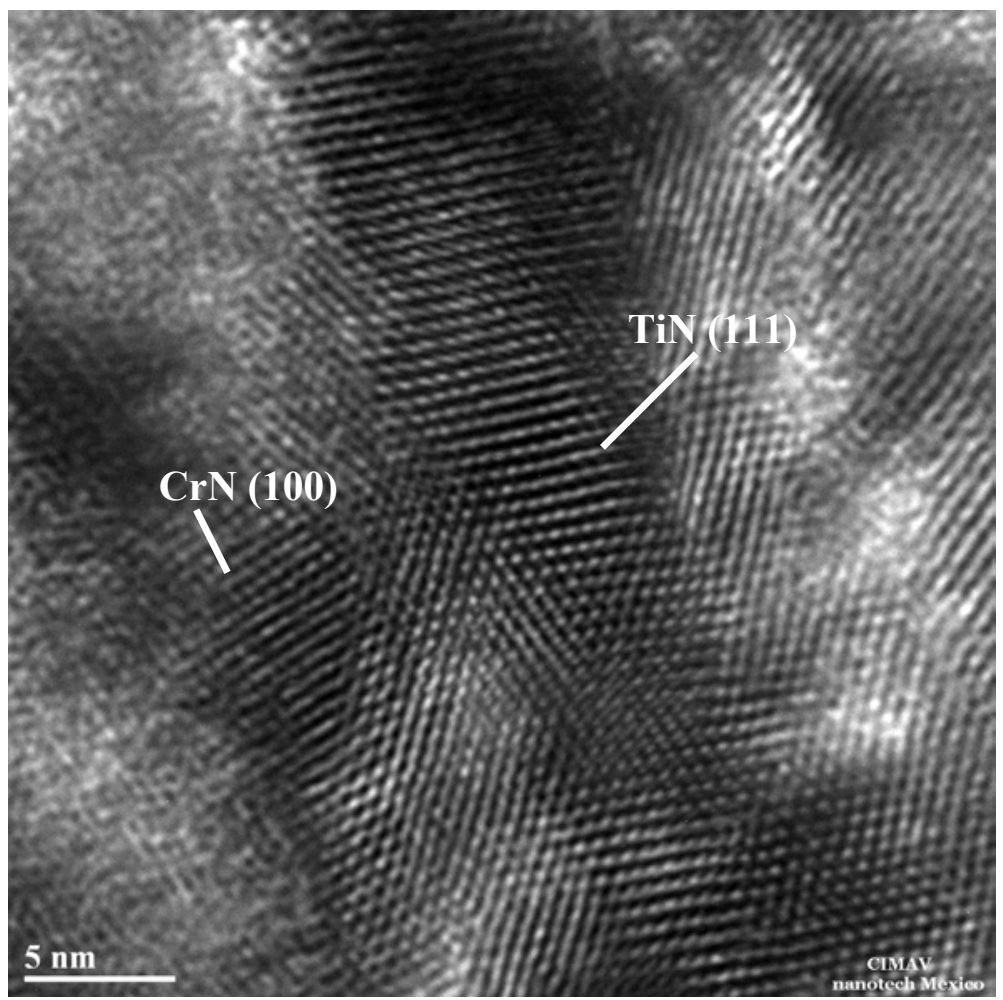

FIG. 2 